\title{
Identifikasi Potensi Ocean Thermal Energy Conversion (Otec) di Selat Makassar Utara
}

\author{
Fadhil Karunia Hammad $^{1 *}$, Baskoro Rochaddi ${ }^{1}$, Purwanto ${ }^{1}$ dan Harjo Susmoro ${ }^{2}$ \\ ${ }^{I}$ Departemen Oseanografi, Fakultas Perikanan dan Ilmu Kelautan, Universitas Diponegoro \\ ${ }^{2}$ Pusat Hrografi-Oseanografi TNI Angkatan Laut \\ Jl. Prof. H. Sudarto, SH, Tembalang Semarang. 50275 Telp/fax (024)7474698 \\ *Email: fadhilhammad@gmail.com
}

\begin{abstract}
Abstrak
Ocean Thermal Energy Conversion (OTEC) adalah salah satu dari banyak sumber energi terbarukan dari lautan yang bisa menjadi solusi untuk energi hijau. Selat Makassar merupakan salah satu wilayah perairan yang sangat berpotensi untuk pembangkit OTEC. Hal tersebut karena Selat Makassar memenuhi kaidah OTEC, dimana termasuk kategori laut dalam dan berada di equator yang memiliki suhu permukaan yang hangat dan konstan, serta memiliki selisih suhu sebesar $20^{\circ} \mathrm{C}$ antara permukaan laut dan laut dalam dengan kedalaman 1000 m. Tujuan dari penelitian ini adalah untuk mengetahui potensi energi OTEC, titik potensial instalasi pembangkit OTEC, dan daya yang dihasilkan di perairan Selat Makassar Utara. Analisa data menggunakan verifikasi metode Root Mean Square Error (RMSE) dan efisiensi OTEC dihitung melalui persaman efisiensi carnot. Besar daya OTEC dihitung dengan asumsi pembangkit OTEC $100 \mathrm{MW}$ menghasilkan $P_{g}$ (daya kotor) dan $P_{n e t}($ daya bersih). Hasil penelitian menunjukkan Selat Makassar memiliki potensi energi OTEC terutama pada stasiun 2 hingga stasiun 17 dengan rata-rata selisih temperatur 23,57 ${ }^{\circ}$ serta efisiensi carnot rata-rata sebesar 7,7\%. Menghasilkan rata-rata daya kotor sebesar 177,66 MW dan daya bersih sebesar 13,85 MW. Titik lokasi yang berpotensi dalam instalasi pembangkit OTEC berada di stasiun 2 dengan koordinat $01^{\circ} 01^{\prime} 51^{\prime \prime} \mathrm{N}$ $120^{\circ} 13^{\prime} 21^{\prime \prime}$ E berupa platform pembangkit floating plants. Jarak dari pantai sepanjang 18,63 km. Memiliki selisih temperatur laut permukaan dan laut dalam $23,3{ }^{\circ} \mathrm{C}$ serta efisiensi carnot sebesar $7,7 \%$ sehingga menghasilkan daya bersih 13,40 MW.
\end{abstract}

Kata Kunci: Daya, Efisiensi Carnot, OTEC, Selat Makassar Utara

\begin{abstract}
Ocean Thermal Energy Conversion (OTEC) is one of the many renewable energy sources from the ocean that can be a solution for green energy. Makassar Strait is one of the territorial waters that has great potential for OTEC plants. That is because the Makassar Strait is included in the deep sea category and on the equator which has a warm and constant surface temperature, and has a temperature difference of $20^{\circ} \mathrm{Cbetween}$ sea level and deep sea with a depth of $1000 \mathrm{~m}$. The purpose of this study is to determine the potential of OTEC energy, the potential OTEC power plant installation, and the power generated in the waters of the North Makassar Strait. Data analysis uses the verification method of Root Mean Square Error (RMSE) and OTEC efficiency is calculated through the carnot efficiency equation. The amount of OTEC power is calculated assuming the 100 MW OTEC generator produces $P_{g}$ (gross power) and $P_{n e t}$ (net power). The results showed that the Makassar Strait has OTEC energy potential especially at stations 2 to station 17 with an average temperature difference of $23.57^{\circ} \mathrm{C}$ and an average carnot efficiency $7.7 \%$. Also produce an average gross power $177.66 \mathrm{MW}$ and a net power $13.85 \mathrm{MW}$. Potential location OTEC power plant installation are at station 2 with coordinates $01^{\circ} 01^{\prime} 51^{\prime \prime} \mathrm{N}-120^{\circ} 13^{\prime} 21^{\prime \prime} \mathrm{E}$ and have a form of floating plants generating platform. The distance from the beach is $18.63 \mathrm{~km}$. It has a difference temperature wich is $23.3^{\circ} \mathrm{Cbetween}$ deep sea and sea surface, and have a $7.7 \%$ carnot efficiency to produce a net power of $13.40 \mathrm{MW}$.
\end{abstract}

Keywords: Carnot efficiency, North Makassar Strait, OTEC, Power Plant

\section{PENDAHULUAN}

Energi baru dan terbarukan telah menjadi harapan masyarakat untuk memenuhi kebutuhan energi. Energi yang melimpah dan ramah lingkungan sangat dinanti-nantikan menjadi andalan pasokan energi suatu negara 
dalam pembangunan masa depan. Selain itu, energi terbarukan yang umumnya lebih bersih, lebih aman dan ramah lingkungan serta ketersediaannya berlimpah sangat dibutuhkan pada semua area di berbagai wilayah. Pemanfaatan sumber daya energi terbarukan di Indonesia masih kurang (Mega dan Syamsuddin, 2015).

Berdasarkan data, kebutuhan energi listrik di Indonesia dipasok oleh tenaga fosil pabrik dengan minyak di peringkat pertama $(51,66 \%)$ dan gas alam di peringkat kedua $(28,57 \%)$. Seperti yang disebutkan oleh Anne (2008) bahwa karena meningkatnya konsumsi energi, kedua energi ini akan berkurang di masa depan, dan OTEC adalah salah satu di antara banyak sumber energi terbarukan dari lautan yang bisa menjadi solusi untuk energi hijau.

OTEC adalah salah satu teknologi terbarukan yang menggunakan perbedaan suhu antara permukaan laut dan kedalaman laut untuk mengoperasikan generator dan menghasilkan energi listrik. Di daerah tropis maritim, sumber daya termal dari termoklin samudera merupakan sumber energi terbarukan yang sangat berpotensi (Duxbury et al., 2002). Berdasarkan posisinya perairan Indonesia, khususnya perairan Selat Makasar menunjukkan suhu yang konstan dan cukup tinggi terutama pada lapisan permukaan (Ilahude dan Gordon, 1996).

Tujuan dari penelitian ini adalah untuk mengidentifikasi potensi energi OTEC yang ada di Selat Makassar Utara, serta menentukan titik lokasi yang berpotensi untuk instalasi pembangkit OTEC di Selat Makassar Utara dan daya yang dapat dihasilkan.

\section{MATERI DAN METODE}

Materi yang digunakan dalam penelitian ini terdiri dari data primer dan data sekunder. Data primer merupakan data pokok yang digunakan pada penelitian ini. Data primer yang digunakan pada penelitian ini adalah suhu vertikal yaitu berupa data suhu lapangan serta data suhu vertikal yang didownload di website HYCOM. Sedangkan Data sekunder tersebut berupa peta bathimetri yang diunduh dari GEBCO. Data suhu vertikal lapangan diukur menggunakan Conductivity, Temperature and Depth (CTD).

Penelitian dilakukan pada bulan Oktober 2018 bersama pihak PUSHIDROSAL yang sedang melaksanakan survei Hidro-Oseanografi di Selat Makassar Utara. Lokasi penelitian di Perairan Selat Makassar Utara berada di bagian antara Pulau Sulawesi dan Pulau Kalimantan. Penentuan titik stasiun pengukuran ditetapkan dari arah barat Selat Makassar Utara dengan koordinat $01^{\circ} 15^{\prime} 17^{\prime \prime} \mathrm{N}-118^{\circ} 49^{\prime} 45^{\prime \prime} \mathrm{E}$ menuju timur Perairan Selat Makassar Utara dengan koordinat $01^{\circ} 01^{\prime} 05^{\prime \prime} \mathrm{N}-120^{\circ} 18^{\prime} 26^{\prime \prime} \mathrm{E}$. Terdapat 19 stasiun yang dapat dilihat pada Gambar 1.

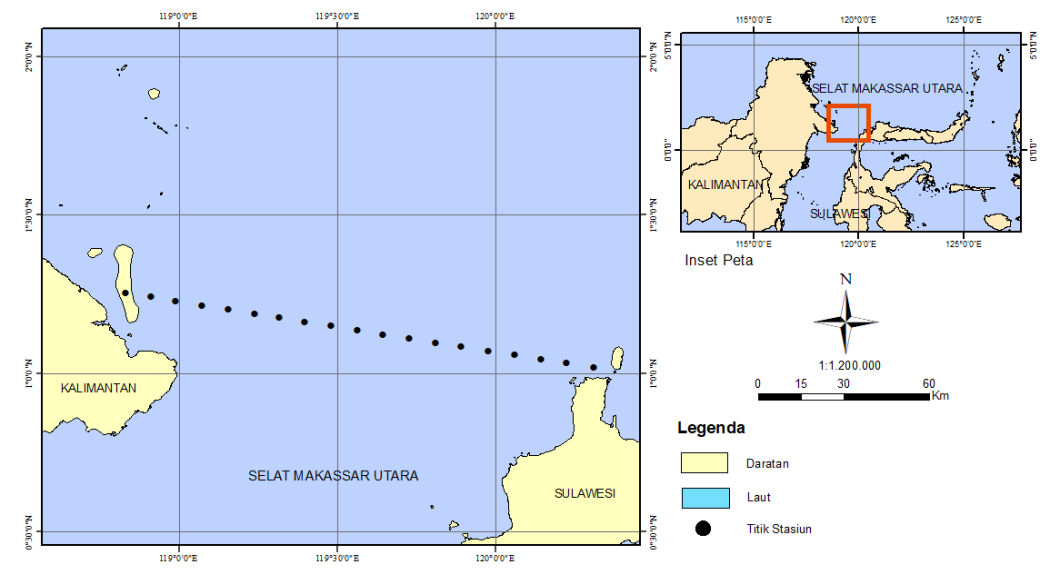

Gambar 1. Lokasi Penelitian Perairan Selat Makassar Utara.

\section{Verifikasi Data Temperatur}

Data suhu yang telah dikumpulkan baik dari pengukuran CTD maupun yang diunduh dari laman https://hycom.org/dataserver/glb-analysis dilakukan validasi data menggunakan uji statistik. Seperti yang dilakukan Mignac et al., (2015) ia melakukan validasi data hycom dengan data insitu dengan menggunakan metode Root Mean Square Deviation (RMSD) atau biasa disebut Root Mean Square Error (RMSE), formulasinya sebagai berikut: 


$$
R M S E=\sqrt{\frac{\sum_{i=1}^{n}\left(X_{o b s, i}-X_{m o d e l, i}\right)^{2}}{n}}
$$

dimana:

$\mathrm{n}=$ jumlah data

$\mathrm{i}=$ data ke-

Xobs $=$ nilai data observasi

Xmodel $=$ nilai data model

Kemudian data suhu diolah dan menghasilkan profil vertikal suhu terhadap kedalaman, lalu menentukan kedalaman pengambilan suhu air hangat dan suhu air dingin yang stabil untuk menghitung nilai selisih perbedaan suhu, dimana minimal nilai $\Delta \mathrm{T}=20^{\circ} \mathrm{C}$. Pada penelitian ini ditentukan intake air panas di kedalaman $20 \mathrm{~m}$, sedangkan penentuan kedalaman intake air dingin berdasarkan pembagian kedalaman yang ditentukan oleh Comfort (2011) pada $800 \mathrm{~m}$.

Sedangkan untuk perairan yang tidak mencapai kedalaman $800 \mathrm{~m}$, penentuan kedalaman intake air dingin di kedalaman $500 \mathrm{~m}$. OTEC memerlukan perbedaan suhu sekitar $20^{\circ} \mathrm{C}$, perbedaan suhu sebesar ini tersedia di antara permukaan air dan di kedalaman kurang lebih $1.000 \mathrm{~m}$ dan sekitar $20^{\circ}$ di ekuator (Adrian, 2015).

\section{Perhitungan Efisiensi dan Besar Daya OTEC}

Nilai efisiensi OTEC dapat dihitung melalui persamaan efisiensi Carnot (Ridho, 2017).

$$
\eta_{(\max )}=\frac{T w-T c}{T w}
$$

keterangan:

$\eta(\max )=$ Efisiensi Carnot

$\mathrm{T}_{\mathrm{w}}=$ Temperatur absolut air hangat

$\mathrm{Tc}=$ Temperatur absolut air dingin

Menurut Nihous (2007) yang menyatakan bahwa, penentuan tangga operasional suhu OTEC yaitu dengan pendekatan suhu minimum pinch point $\Delta \mathrm{T} / 16$ pada kondisi standar baik evaporator atau kondensor yang dipilih untuk mempertahankan pertukaran panas yang terjadi dalam sistem OTEC. Penurunan suhu air laut yang dingin di permukaan (Dcws) oleh $3 \Delta \mathrm{T} /\{8(1+\gamma)\}$ di evaporator dan suhu air laut dalam yang hangat (Dwwd) $3 \gamma \Delta \mathrm{T} /\{8(1+\gamma)\}$ di kondensor. Besar daya OTEC yang dihitung pada penelitan ini menggunakan pembangkit OTEC sebesar $100 \mathrm{MW}$ dengan menggunakan asumsi seperti yang dilakukan oleh Morales (2014). Daya kotor listrik yang dihasilkan adalah hasil dari beban panas evaporator dan efisiensi termodinamika:

$$
P_{g}=\frac{Q_{w w} \rho C_{p} 3 \eta \varepsilon_{t g}}{16(1+\eta) T} \Delta T^{2}
$$

dimana,

$\rho=$ rerata densitas air laut $(1025 \mathrm{~kg} / \mathrm{m} 3)$

$\mathrm{Cp}=$ heat spesifik air laut $(4 \mathrm{~kJ} / \mathrm{kg} \mathrm{K})$

$\mathrm{Q}=$ rasio yang mewakili laju aliran suhu air hangat $(\mathrm{Qww}=10 \mathrm{~m} 3 / \mathrm{s})$ dan air dingin $(\mathrm{Qcw}=5 \mathrm{~m} 3 / \mathrm{s})$.

$\varepsilon$ tg $=$ entalpi turbo generator (turbogenerator efficiency).

$\eta=$ ratio of cold seawater flow rate over warm seawater flow rate in OTEC process $(0,5)$.

Kemudian daya bersih $\left(\mathrm{P}_{\text {net }}\right)$ diperkirakan dengan mempertimbangkan daya konsumsi yang dibutuhkan untuk mendorong kecepatan aliran besar air laut melewati pembangkit OTEC dari $\mathrm{P}_{\mathrm{g}}$ dengan desain kondisi $(\Delta \mathrm{T}$ design $=20^{\circ} \mathrm{C}$ ), dan daya yang hilang lainnya diberikan pada:

$$
P_{n e t}=\frac{Q_{w w} \rho C_{p} 3 \eta \varepsilon_{t g}}{16(1+\eta) T}\left\{\Delta T^{2}-0,3 \Delta \mathrm{T}_{\text {design }}^{2}\right\}
$$


Persamaan produksi daya kotor menggabungkan efisiensi Carnot, Carnot menuju Rankine, dan keseimbangan panas di seluruh evaporator. Rumus untuk $\mathrm{P}_{\mathrm{g}}$ dimodifikasi dari persamaan yang diberikan oleh Nihous (2007) untuk mengakomodasi asumsi kepatutan yang dibuat oleh Lockheed Martin dan kemudian disederhanakan menjadi persamaan linear:

$$
P_{g}=\frac{106,22 \Delta T^{2}}{T s-0,25 \Delta T+273,15}
$$

\section{Metode Penentuan Kelerengan Dasar Laut}

Data akurat nilai kedalaman adalah data kedalaman yang dikoreksi terhadap elevasi muka air laut yang berubah setiap waktu. Data terkoreksi tersebut sebagai dasar pemetaan yang akan diolah menghasilkan nilai kedalaman. Selain itu, diperoleh juga nilai kemiringan dasar laut yang dapat dihitung menggunakan rumus (Daniel, 1994):

Keterangan :

$$
\tan \alpha=\mathrm{DH} / \mathrm{L}(2,4)
$$

$\alpha$ : besarnya sudut $\left({ }^{\circ}\right)$ kemiringan dasar laut (slope)

$\mathrm{DH}$ : selisih elevasi antara dua kontur batimetri (m)

$\mathrm{L}$ : jarak horizontal (tegak lurus) antara kedua garis kontur batimetri (m)

Avery dan Wu (1994) menerangkan bahwa pembangkit OTEC harus dibangun di lokasi yang sesuai untuk mencegah terjadinya perubahan signifikan pada ekologi lokal. Sebagai pertimbangan tersebut, Marine Protected Areas Network digunakan sehingga didapat titik lokasi yang ideal dan juga dapat diketahui jarak titik dari pantai.

\section{HASIL DAN PEMBAHASAN}

\section{Karakteristik Perairan Selat Makassar}

Seperti keadaan laut pada umumnya, suhu permukaan Selat Makasar juga dipengaruhi oleh kondisi cuaca antara lain curah hujan, penguapan, kelembaban udara, kecepatan angin dan penyinaran matahari. Oleh karena itu keadaan suhu selalu berpola musiman.

Berdasarkan posisinya, perairan Indonesia, khususnya perairan Selat Makasar menunjukkan suhu yang cukup tinggi terutama pada lapisan permukaan. Karena pengaruh angin, maka lapisan teratas sampai kedalaman tertentu, yakni kedalaman 50-100 m terjadi pengadukan dan pencampuran, sehingga suhu pada lapisan 0-100 m menjadi homogen. Dengan adanya pergerakan massa air dan pergantian angin musim, maka lapisan homogen ini dapat bervariasi kedalamannya antara 0-100 m pada musim barat dan 0-50 m pada musim timur (Ilahude dan Gordon, 1996).

Hasil temperatur permukaan rerata bulanan tahun 2009-2018 disajikan dalam Gambar 12. Berdasarkan gambar tersebut dapat diketahui rata-rata temperatur bulanan lapisan permukaan dari stasiun 1 hingga stasiun 19 dengan jangka waktu 10 tahun yaitu 2009-2018.

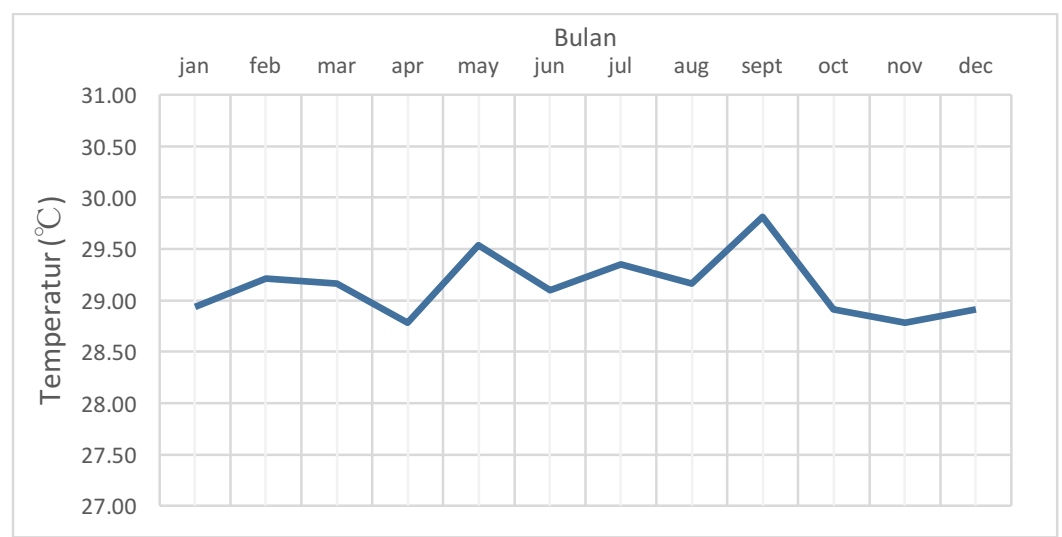

Gambar 2. Temperatur Permukaan Laut Rerata Bulanan Tahun 2009-2018. 
Temperatur pada lapisan permukaan berkisar antara $28,60^{\circ} \mathrm{C}-29,65^{\circ} \mathrm{C}$, hal ini dapat terjadi karena letak perairan Selat Makassar berada pada daerah tropis yang dekat dengan garis ekuator sehingga memungkinkan adanya pengaruh atau bagian dari kolam air hangat tropikal (Warm Pool of Tropical) Samudera Pasifik.

Menurut Ilhaude dan Gordon (1996) kolam air hangat tropikal ditandai dengan temperatur permukaan yang lebih besar dari $28^{\circ} \mathrm{C}$. Pada bulan April hingga September terjadi kenaikan temperatur hingga kisaran $29,5^{\circ} \mathrm{C}$, hal ini dikarenakan berlangsungnya musim kemarau di Indonesia bersamaan dengan bertiupnya angin musim timur. Sedangkan pada bulan Oktober hingga Februari berlangsung musim hujan yang diakibatkan bertiupnya angin musim barat sehingga mengalami penurunan temperatur hingga $28^{\circ} \mathrm{C}$. Dapat disimpulkan bahwa temperatur pada perairan Selat Makassar tidak memiliki perubahan yang signifikan atau bisa dikatakan konstan.

\section{Verifikasi Data Temperatur}

Untuk mengevaluasi dan mengetahui keakuratan data HYCOM, maka dilakukan verifikasi data menggunakan hasil distribusi vertikal temperatur antara data HYCOM dengan data CTD.

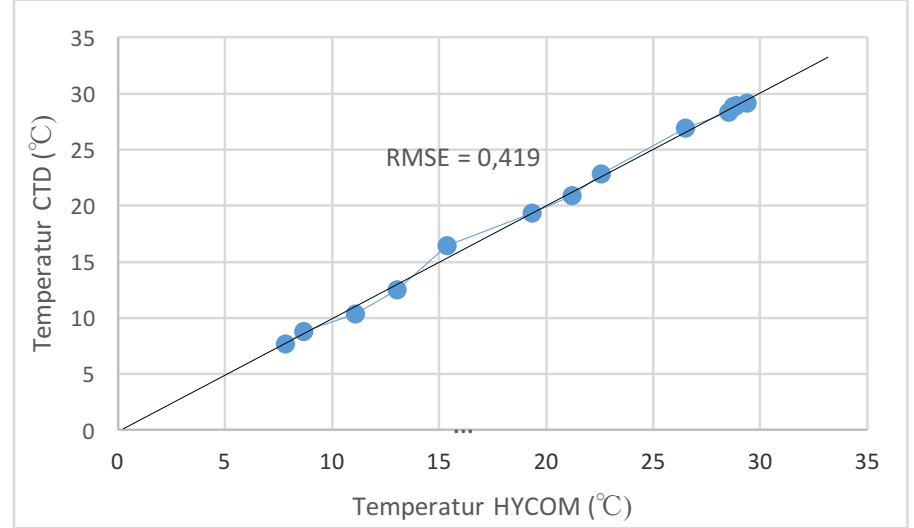

Gambar 3. Sebaran Perbandingan Nilai Temperatur antara Data CTD dengan HYCOM. 
Verifikasi data dilakukan dengan menggunakan hasil pengolahan distribusi temperatur vertikal antara data HYCOM dengan data lapangan CTD dihitung menggunakan metode RMSE. Verifikasi dilakukan pada stasiun 7 dengan koordinat $01^{\circ} 05^{\prime} 46^{\prime \prime} \mathrm{N} 119^{\circ} 48^{\prime} 30^{\prime \prime} \mathrm{E}$ pada data CTD serta dengan koordinat $01^{\circ} 04^{\prime} 0{ }^{\prime \prime} \mathrm{N}$ $19^{\circ} 56^{\prime} 0^{\prime \prime E}$ untuk data HYCOM. Hasil RMSE tersebut adalah 0,4197 seperti yang tertera pada Gambar 3, menunjukkan hasil keakuratan yang paling baik dikarenakan memiliki perbandingan nilai yang tidak besar antara data pengukuran model dan data pengukuran observasi dan mendekati nilai 0 menurut hasil verifikasi yang dilakukan oleh Mignac et al., (2015).

hubungan antara data temperatur CTD dan HYCOM menunjukan hasil yang cukup baik karena grafik sebaran data mendekati garis linear. Apabila dilihat dari nilai error yang terjadi, maka data HYCOM dapat dianggap mampu merepresentasikan kondisi temperatur dari pengambilan data lapangan CTD.

\section{Analisis Data Temperatur Laut}

Data temperatur laut dianalisa secara temporal dan diinterpretasikan melalui grafik sebaran temperatur vertikal disetiap stasiun pengamatan. Analisa dilakukan di beberapa titik dengan kedalaman $900 \mathrm{~m}$ dari data HYCOM. Data tersebut memiliki data per-satu hari selama Mei 2009-November 2018, lalu dirata-ratakan setiap bulan. Berdasarkan hasil plot distribusi temperatur vertikal HYCOM, dapat diperoleh temperatur air laut hangat di permukaan (Tws) dan temperatur air laut dingin di kedalaman (Tcs) untuk memperoleh selisih temperatur $(\Delta \mathrm{T})$ antara permukaan laut dan kedalaman laut. Sedangkan data CTD dianalisa dengan kedalaman $500 \mathrm{~m}$. Berdasarkan hasil plot distribusi termperatur gradien CTD diperoleh sebaran suhu vertikal dan horizontal.

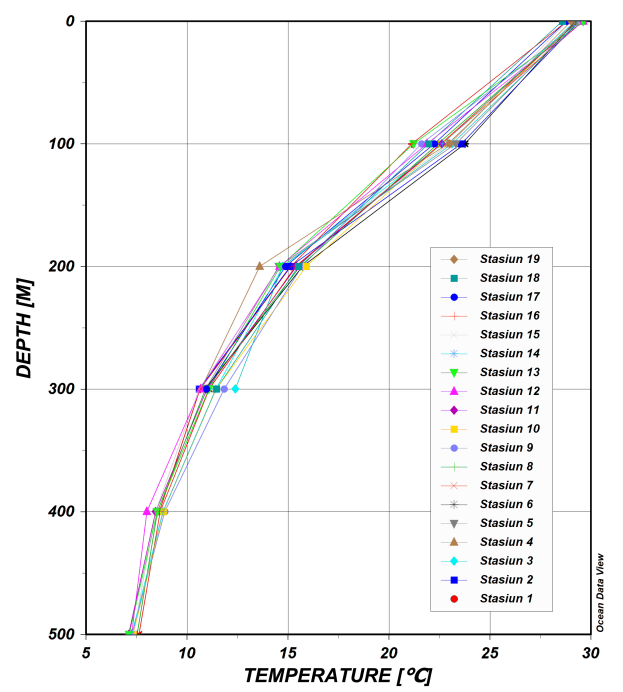

Gambar 4. Sebaran Temperatur CTD Vertikal.

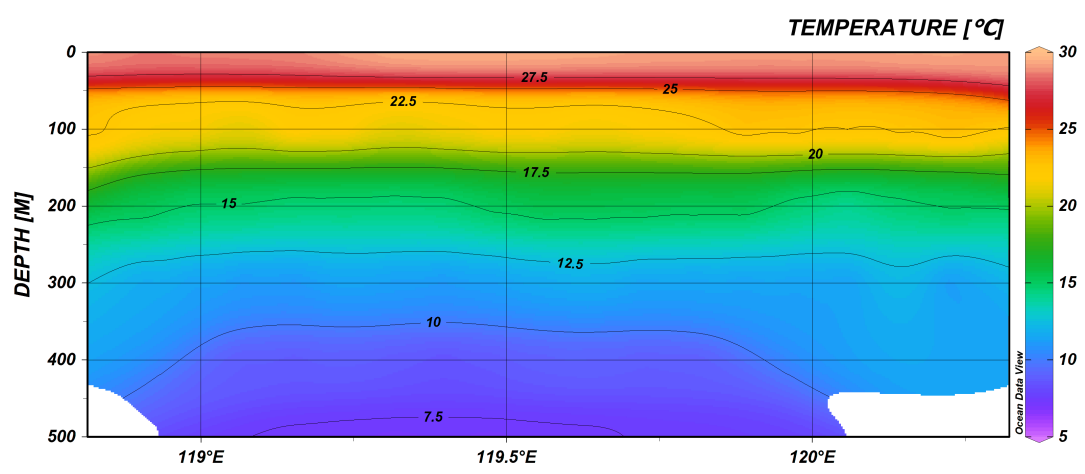

Gambar 5. Sebaran Temperatur CTD Horizontal.

Grafik pada Gambar 4 dan Gambar 5 memiliki pola yang konstan disetiap stasiunnya dikarenakan tidak adanya perubahan yang signifikan dari stasiun 1 hingga stasiun 19. Pada kedalaman $400 \mathrm{~m}$ sudah memiliki 
perbedaan suhu sebesar $20,37^{\circ} \mathrm{C}-21,60^{\circ} \mathrm{C}$ yang merupakan nilai minimum untuk menjalankan OTEC. Terdapat berbagai titik stasiun memiliki kedalaman tidak mencapai hingga $400 \mathrm{~m}$ yaitu pada stasiun 1, 2, 3, 4, 18 dan 19 yang dapat dilihat pada Gambar 5 sehingga menghasilkan warna putih pada sebaran temperatur. Hal ini dapat terjadi karena memang kedalaman tidak mencapai $400 \mathrm{~m}$ atau karena kesalahan / error dalam pengukuran berlangsung.

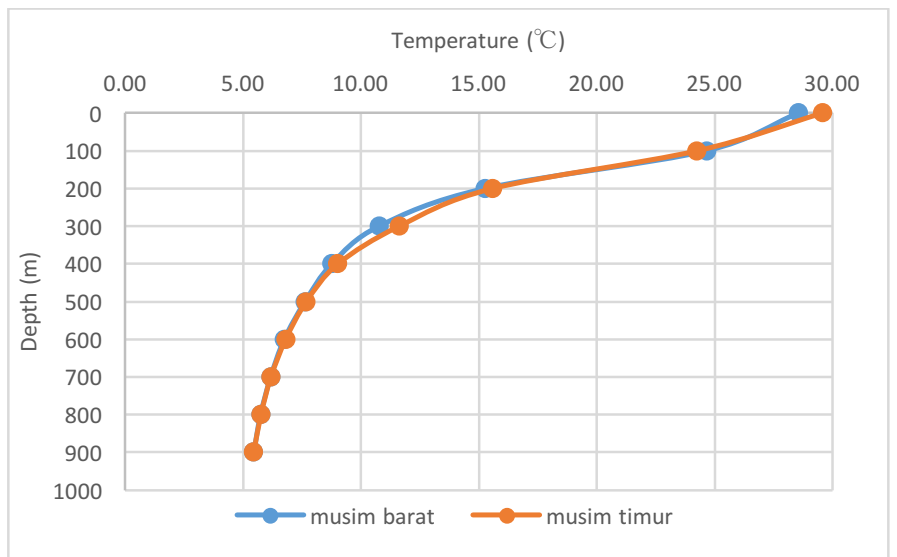

Gambar 6. Plot Distribusi Vertikal Temperatur Laut Rerata Bulanan Tahun 2009-2018 di Stasiun 2.

Sepanjang tahun 2009-2018 temperatur permukaan pada titik stasiun memiliki perbedaan setiap musimnya. Pada bulan Oktober hingga Maret temperatur permukaan memiliki rata-rata sebesar $28,54^{\circ} \mathrm{C}$. Sedangkan pada bulan April hingga September temperatur permukaan lebih tinggi dengan rata-rata sebesar $29,56^{\circ} \mathrm{C}$. Hal tersebut dapat terjadi karena angin muson barat bertiup pada bulan Oktober sampai April, yaitu pada saat posisi semu matahari di berada belahan bumi selatan. Posisi inilah yang menyebabkan tekanan udara yang tinggi di Asia dan tekanan udara yang rendah di wilayah Australia membuat angin bertiup dari benua Asia ke benua Australia. Sebaliknya angin muson timur bertiup pada bulan April sampai Oktober. Ketika letak semu matahari di sebelah belahan bumi utara, sehingga menyebabkan tekanan udara wilayah benua Asia menjadi rendah dan tekanan udara wilayah benua Australia menjadi tinggi. Hal tersebut menyebabkan angin bertiup dari benua Australia ke Benua Asia. Berdasarkan posisinya, perairan Indonesia, khususnya perairan Selat Makasar menunjukkan suhu yang cukup tinggi terutama pada lapisan permukaan (Ilahude dan Gordon, 1996).

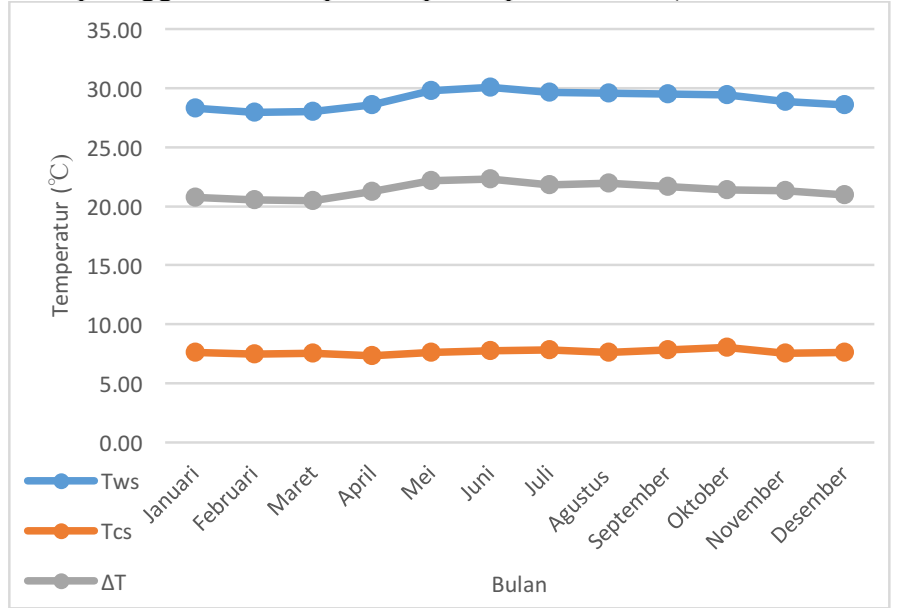

Gambar 7. Grafik Temperatur Permukaan Air Laut (Tws), Temperatur Air Laut Kedalaman (Tcs), dan Selisih Temperatur $(\Delta \mathrm{T})$ Rerata Bulanan Tahun 2009-2018 di Stasiun 2.

Lapisan kedalaman laut juga dapat dilihat dari perubahan suhu yang terjadi di dalam laut. Faktor yang mempengaruhi adanya perubahan suhu di dalam laut adalah jumlah cahaya matahari yang masuk ke dalam laut. Selain itu posisi laut tersebut mempengaruhi suhu didalam laut. Temperatur pada air laut hangat sepanjang tahunnya tidak memiliki perubahan yang signifikan dengan rata-rata bulanan sebesar $29,05^{\circ} \mathrm{C}$. Menurut Lewis et 
al., (2011), hal ini termasuk dalam wilayah mixed layer yaitu lapisan kedalam laut dengan kedalaman sekitar 0 hingga $100 \mathrm{~m}$ atau beberapa kasus tergantung wilayah perairannya. Lapisan ini masih dapat di jangkau oleh matahari. Lapisan ini terbentuk akibat adanya pengaruh angin serta gelombang air laut, yang membuat daerah ini menjadi teraduk, dan menciptakan lapisan homogen. Temperatur pada air laut dingin juga memiliki grafik yang konstan jika dilihat pada Gambar 7 dengan nilai rata-rata sebesar $5,75^{\circ} \mathrm{C}$ yang merupakan intake air dingin pada operasi OTEC pada kedalaman $800 \mathrm{~m}$ menurut Comfort (2011). Kedalaman tersebut termasuk dalam thermocline yaitu lapisan kedalaman laut pada kedalaman sekitar $100 \mathrm{~m}$ hingga $1500 \mathrm{~m}$. Pada lapisan ini, perubahan temperatur air laut berlangsung sangat cepat. Air laut yang bermula hangat mendadak menjadi lebih dingin secara tiba-tiba. Hal ini terjadi karena perubahan cahaya matahari yang masuk ke dalam laut. Nilai perubahan temperatur pada thermocline yang diperoleh dari penelitian berkisar $5^{\circ} \mathrm{G}-24,46^{\circ} \mathrm{C}$ dengan kedalaman 100-900 m. Seperti yang dikemukakan oleh Song et al., (2007), dalam lapisan ini suhu mengalami perubahan yang drastis, penurunan suhu ini terjadi seiring bertambahnya kedalaman.

\section{Efisiensi Carnot dan Daya OTEC}

Besar daya OTEC yang dihitung pada penelitan ini menggunakan pembangkit OTEC sebesar $100 \mathrm{MW}$ dengan menggunakan asumsi seperti yang dilakukan oleh Morales (2014). Hasil dari perbedaan temperatur permukaan air laut dengan temperatur air laut kedalaman yaitu selisih temperatur dapat dipergunakan untuk menentukan besar daya OTEC. Efisiensi Carnot dapat ditentukan dengan mengubah temperatur menjadi absolute temperature atau suhu mutlak terlebih dahulu. Untuk menghasilkan efisiensi Carnot dan daya yang baik maka dibutuhkannya selisih temperatur lebih dari $20^{\circ} \mathrm{C}$ menurut SERI (1989). Stasiun yang telah memenuhi kualifikasi tersebut yaitu stasiun 2-17. Hasil tersebut dapat dilihat pada Tabel 1.

Tabel 1. Efisiensi Carnot dan Daya OTEC

\begin{tabular}{|c|c|c|c|c|c|c|c|c|c|}
\hline \multirow{2}{*}{ Stasiun } & \multicolumn{2}{|c|}{ POSISI } & \multirow{2}{*}{$\begin{array}{l}\text { Depth } \\
\text { (m) }\end{array}$} & \multirow{2}{*}{$\begin{array}{l}\mathbf{T}_{\mathbf{w s}} \\
\left({ }^{\circ} \mathbf{K}\right) \\
\end{array}$} & \multirow{2}{*}{$\begin{array}{l}\mathbf{T}_{\text {es }} \\
\left({ }^{\circ} \mathrm{K}\right) \\
\end{array}$} & \multirow{2}{*}{$\begin{array}{l}\Delta \mathbf{T} \\
\left({ }^{\circ} \mathrm{C}\right) \\
\end{array}$} & \multirow{2}{*}{$\begin{array}{c}\text { Efisiensi Carnot } \\
\text { (nmaks) }\end{array}$} & \multirow{2}{*}{$\begin{array}{c}\text { Nilai Pgross } \\
\text { MW }\end{array}$} & \multirow{2}{*}{$\begin{array}{c}\text { Nilai Pnet } \\
\text { MW }\end{array}$} \\
\hline & Lintang (U) & Bujur (T) & & & & & & & \\
\hline 2 & $01^{\circ} 01^{\prime} 51 " \mathrm{~N}$ & $120^{\circ} 13^{\prime} 21^{\prime \prime} \mathrm{E}$ & 900 & 302,20 & 278,9 & 23,30 & 0,0771 & 173,927 & 13,4100 \\
\hline 3 & $01^{\circ} 02^{\prime} 36^{\prime \prime N}$ & $120^{\circ} 08^{\prime} 25^{\prime \prime} \mathrm{E}$ & 900 & 302,31 & 278,69 & 23,62 & 0,0781 & 178,3718 & 13,9365 \\
\hline 4 & $01^{\circ} 03^{\prime} 25^{\prime \prime N}$ & $120^{\circ} 03^{\prime} 25^{\prime \prime} \mathrm{E}$ & 900 & 302,33 & 278,67 & 23,66 & 0,0783 & 178,9274 & 14,0027 \\
\hline 5 & $01^{\circ} 04^{\prime} 13^{\prime \prime N}$ & $119^{\circ} 58^{\prime} 29^{\prime \prime E}$ & 900 & 302,29 & 278,63 & 23,66 & 0,0783 & 178,9274 & 14,0045 \\
\hline 6 & $01^{\circ} 05^{\prime} 02^{\prime \prime N}$ & $119^{\circ} 53^{\prime 22 " E}$ & 900 & 302,20 & 278,47 & 23,73 & 0,0785 & 179,8997 & 14,1265 \\
\hline 7 & $01^{\circ} 05^{\prime} 46^{\prime \prime} \mathrm{N}$ & $119^{\circ} 48^{\prime} 30^{\prime \prime E}$ & 900 & 302,15 & 278,82 & 23,33 & 0,0772 & 174,3437 & 13,4617 \\
\hline 8 & $01^{\circ} 06^{\prime} 33^{\prime \prime N}$ & $119^{\circ} 43^{\prime} 30 " \mathrm{E}$ & 900 & 302,15 & 278,28 & 23,87 & 0,0790 & 181,8443 & 14,3658 \\
\hline 9 & $01^{\circ} 07^{\prime} 20 " \mathrm{~N}$ & $119^{\circ} 38^{\prime} 35^{\prime \prime} \mathrm{E}$ & 900 & 302,15 & 278,63 & 23,52 & 0,0778 & 176,9828 & 13,7767 \\
\hline 10 & $01^{\circ} 08^{\prime} 07^{\prime \prime N}$ & $119^{\circ} 33^{\prime} 41^{\prime \prime E}$ & 900 & 302,24 & 278,57 & 23,67 & 0,0783 & 179,0663 & 14,0236 \\
\hline 11 & $01^{\circ} 09^{\prime} 02^{\prime \prime} \mathrm{N}$ & $119^{\circ} 28^{\prime} 46^{\prime \prime} E$ & 900 & 302,19 & 279,01 & 23,18 & 0,0767 & 172,2602 & 13,2135 \\
\hline 12 & $01^{\circ} 09^{\prime} 46 " \mathrm{~N}$ & $119^{\circ} 23^{\prime} 47^{\prime \prime} \mathrm{E}$ & 900 & 302,16 & 278,29 & 23,87 & 0,0790 & 181,8443 & 14,3653 \\
\hline 13 & $01^{\circ} 10^{\prime} 31^{\prime \prime N}$ & $119^{\circ} 18^{\prime} 58^{\prime \prime} \mathrm{E}$ & 900 & 302,18 & 278,51 & 23,67 & 0,0783 & 179,0663 & 14,0264 \\
\hline 14 & $01^{\circ} 11^{\prime} 17^{\prime \prime N}$ & $119^{\circ} 14^{\prime} 09^{\prime \prime} \mathrm{E}$ & 900 & 302,23 & 278,8 & 23,43 & 0,0775 & 175,7327 & 13,6235 \\
\hline 15 & $01^{\circ} 12^{\prime} 02^{\prime \prime N}$ & $119^{\circ} 09^{\prime} 10^{\prime \prime} \mathrm{E}$ & 900 & 302,20 & 278,68 & 23,52 & 0,0778 & 176,9828 & 13,7744 \\
\hline 16 & $01^{\circ} 12^{\prime} 51^{\prime \prime N}$ & $119^{\circ} 04^{\prime} 11 " \mathrm{E}$ & 900 & 302,15 & 278,72 & 23,43 & 0,0775 & 175,7327 & 13,6271 \\
\hline 17 & $01^{\circ} 13^{\prime} 41^{\prime \prime} \mathrm{N}$ & $118^{\circ} 59^{\prime} 19^{\prime \prime} \mathrm{E}$ & 900 & 302,04 & 278,39 & 23,65 & 0,0783 & 178,7885 & 13,9993 \\
\hline
\end{tabular}

Stasiun 1, 2 dan 19 tidak memenuhi kriteria karena memeliki kedalaman kurang dari $400 \mathrm{~m}$ sehingga selisih temperatur antara batas atas dan batas bawah tidak mencapai $20^{\circ} \mathrm{C}$. Nilai efisiensi memiliki hubungan yang erat dengan selisih temperatur, dimana semakin besar nilai selisih temperatur maka semakin besar pula nilai efisiensinya (Charlier, 2003). Hal tersebut dapat dibuktikan pada Tabel 1 dengan selisih terkecil yaitu pada stasiun 11 dengan suhu $23,18^{\circ} \mathrm{C}$ menghasilkan efisiensi sebesar 0,0767 (7,67\%), sedangkan selisih terbesar pada stasiun 12 dengan suhu $23,96^{\circ} \mathrm{C}$ menghasilkan efisiensi sebesar 0,0792 (7,92\%). Nilai efisiensi OTEC pada Selat Makassar cocok untuk menjalankan sistem OTEC karena secara teoritis memiliki nilai efisiensi yang memenuhi syarat yaitu 7,5\% sampai 8\% menurut Avery dan $\mathrm{Wu}(1994)$.

Perbedaan suhu yang didapatkan antara dipermukaan laut dengan dikedalaman harus dikonversikan agar dapat diketahui besar daya energi yang dihasilkan. Daya OTEC dihitung dengan menggunakan persamaan dari Nihous (2007). Daya kotor listrik yang dihasilkan adalah hasil dari beban panas evaporator dan efisiensi termodinamika dengan rata-rata sebesar 177,66 MW Nilai rata-rata $P_{\text {net }}$ berkisar 13,85 MW dengan nilai terbesar 14,51 MW pada stasiun 12 dan nilai terkecil 13,21 MW pada stasiun 11. Dengan daya tersebut dapat membantu memenuhi kebutuhan di beberapa wilayah.

\section{Stasiun Ideal Instalasi OTEC}

Studi menunjukkan bahwa fasilitas OTEC dapat ditempatkan di darat, dekat pantai, platform yang melekat pada landas kontinen, atau pada laut dalam. Adapun beberapa pertimbangan dasar untuk instalasi OTEC meliputi beberapa aspek sebagai berikut; Lingkungan yang stabil untuk pengoperasian sistem, sumber air hangat 
dan dingin yang konstan dengan perbedaan suhu minimum $20^{\circ} \mathrm{C}$, serta hemat biaya dalam menghasilkan daya dan produk pelengkap menurut Solar Energy Research Institute (1989). Disisi lain, pembangkit OTEC tidak akan mampu menahan badai laut melampaui masa hidupnya. Korosi oleh air garam, erosi karena aliran volume besar, biofouling karena pertumbuhan ganggang, lapisan karang oleh berbagai hewan laut seperti remis, dan gelombang arus yang tinggi juga dapat mempengaruhi sistem kerja OTEC.

Menurut Ilahude dan Gordon (1996), arus yang mengalir di Selat Makassar pada lapisan permukaan sangat dipengaruhi oleh angin muson, sehingga pola alirannya akan mengikuti siklus dari angin muson. Selain angin yang mempengaruhi pergerakan arus permukaan, di perairan Selat Makassar juga dipengaruhi oleh kondisi geografis Selat Makassar. Arus yang mengalir di Selat Makassar secara tetap mengalir sepanjang tahun menuju ke selatan dan dengan kecepatan yang cukup sedang sehingga tidak terlalu memberikan dampak pada kinerja OTEC itu sendiri.

Tabel 2. Data Geografis antar Stasiun

\begin{tabular}{|c|c|c|c|c|c|}
\hline \multirow{2}{*}{ Stasiun } & \multicolumn{2}{|c}{ POSISI } & Maks Depth & $\begin{array}{c}\text { Kelerengan } \\
\text { Dasar Laut }\end{array}$ & $\begin{array}{c}\text { Jarak } \\
\text { Antar Stasiun }\end{array}$ \\
\cline { 2 - 5 } & Lintang (U) & Bujur (T) & $\mathbf{( m )}$ & $\mathbf{( 0 )}$ & $\mathbf{( K M )}$ \\
\hline 2 & 1,0310 & 120,2225 & 917 & 10,077 & 9,241 \\
\hline 3 & 1,0433 & 120,1403 & 1537 & 6,112 & 9,395 \\
\hline 4 & 1,0569 & 120,0569 & 2563 & 3,613 & 9,259 \\
\hline 5 & 1,0703 & 119,9747 & 3212 & 2,990 & 9,603 \\
\hline 6 & 1,0839 & 119,8894 & 3124 & 2,919 & 9,118 \\
\hline 7 & 1,0961 & 119,8083 & 2897 & 3,236 & 9,375 \\
\hline 8 & 1,1092 & 119,7250 & 2835 & 3,252 & 9,219 \\
\hline 9 & 1,1222 & 119,6431 & 2782 & 3,307 & 9,199 \\
\hline 10 & 1,1353 & 119,5614 & 2894 & 3,204 & 9,274 \\
\hline 11 & 1,1506 & 119,4794 & 2749 & 3,393 & 9,326 \\
\hline 12 & 1,1628 & 119,3964 & 2875 & 3,142 & 9,035 \\
\hline 13 & 1,1753 & 119,3161 & 2964 & 3,050 & 9,040 \\
\hline 14 & 1,1881 & 119,2358 & 3347 & 2,788 & 9,331 \\
\hline 15 & 1,2006 & 119,1528 & 2584 & 3,623 & 9,361 \\
\hline 16 & 1,2142 & 119,0697 & 2031 & 4,504 & 9,147 \\
\hline 17 & 1,2281 & 118,9886 & 1427 & 6,299 & 8,988 \\
\hline
\end{tabular}

Stasiun 12 memiliki daya yang paling besar dengan daya sebesar 14,52 MW tetapi memiliki jarak tempuh yang sangat jauh yaitu $64 \mathrm{~km}$ dari daratan, sehingga hal tersebut sangat tidak efisien dalam pengiriman daya. Seperti yang sudah disinggungkan oleh Solar Energy Research Institute (1989) bahwa biaya akomodasi merupakan salah satu aspek pertimbangan dalam menentukan lokasi instalasi pembangkit OTEC. Gambar 51 menunjukan bahwa pada penelitian ini stasiun paling ideal yaitu pada stasiun 2 dapat dilihat pada Gambar 8, karena berdekatan dengan daratan dan juga menghasilkan daya yang cukup besar yaitu 13,41 MW. Sedangkan platform yang paling ideal yaitu floating plants. Mengingat jika menggunakan land-based pada stasiun 2 dengan jarak 18,63 km dari daratan dan memiliki kelerangan dasar laut yang landai dengan kelerangan $10,067^{\circ}$ jika dilihat pada Tabel 2, dimana membutuhkan pipa yang panjang dan mendapatkan gangguan turbulen gelombang pada surf zone. Sehingga membutuhkan perawatan yg lebih dan memakan biaya yang besar. Kerugian lain yaitu pembuangan air dari pipa dapat menyebabkan kematian dengan perubahan temperatur $3-4^{\circ} \mathrm{C}$ pada ikan dan karang karena efek thermal yang dapat merubah suhu sekitar.

Berdasarkan hasil tersebut, OTEC dapat dijadikan sebagai energi alternatif dalam jangka waktu yang panjang ditengah kelangkaan energi fosil maupun gas alam dan energi lainnya. Dengan energi yang ramah lingkungan serta memiliki sumber ketersediaan yang tidak terbatas. Tetapi biaya menjadi pertimbangan dalam mengaplikasikan OTEC dengan modal pembangunan, biaya perawatan, dan biaya akomodasi yang terhitung tidak sedikit jumlahnya. Tidak hanya itu, OTEC juga memiliki efficiency mesin yang terhitung kecil jika dibandingkan dengan pembangkit listrik pada umumnya. Tetap saja jika dipergunakan dalam jangka waktu yang panjang biaya tidak akan menjadi suatu masalah untuk pembangkit OTEC. 


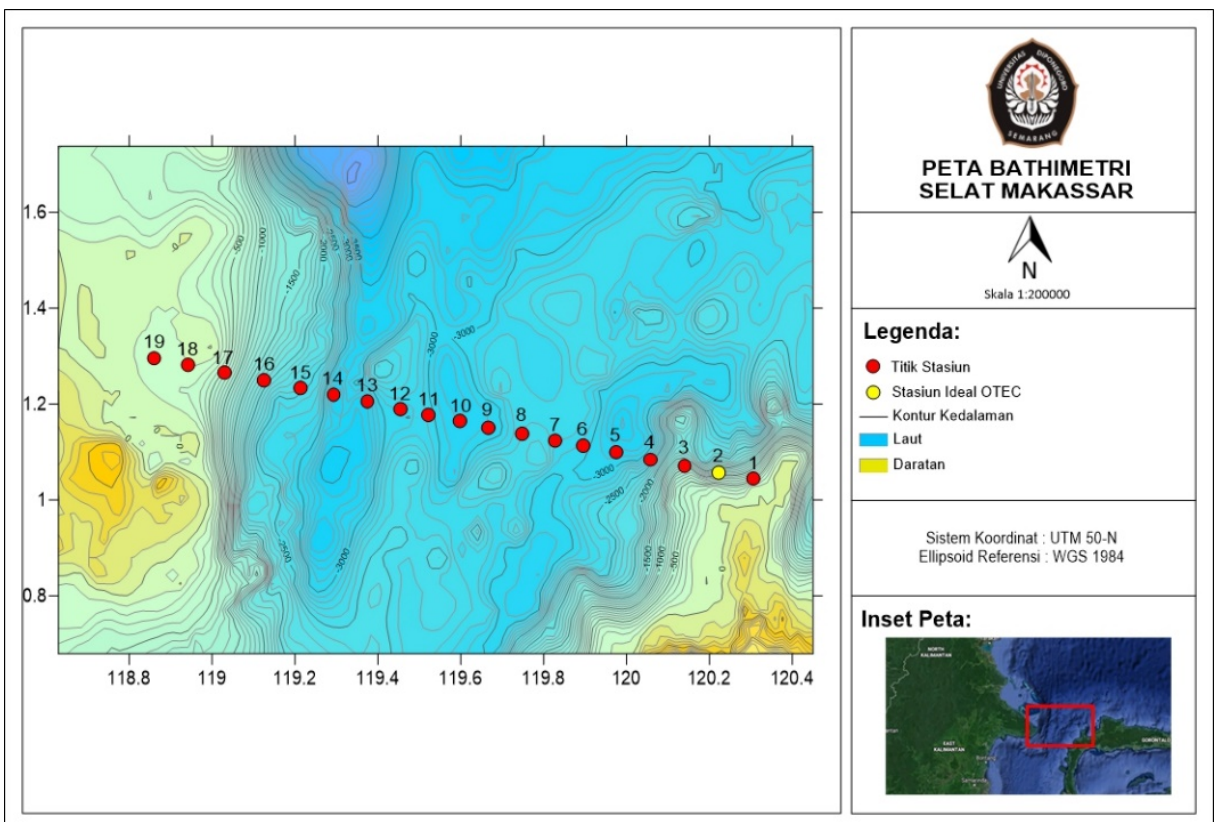

Gambar 8. Peta Instalasi Pembangkit OTEC di Selat Makassar Utara Berdasarkan Data General Bathymetry Chart of the Ocean (GEBCO) Tahun 2014.

\section{KESIMPULAN}

Selat Makassar memiliki potensi energi OTEC terutama pada stasiun 2 hingga stasiun 17 dengan rata-rata selisih temperatur $23,57^{\circ} \mathrm{C}$ serta efisiensi Carnot rata-rata sebesar 7,7\%. Menghasilkan rata-rata daya kotor sebesar 177,66 MW dan daya bersih sebesar 13,85 MW. 2. Titik lokasi yang berpotensi dalam instalasi pembangkit OTEC berada di stasiun 2 pada koordinat $01^{\circ} 01^{\prime} 51^{\prime \prime} \mathrm{N}-120^{\circ} 13^{\prime} 21^{\prime \prime} \mathrm{E}$ dengan platform pembangkit floating plants. Jarak dari pantai sepanjang $18,63 \mathrm{~km}$. Serta memiliki selisih temperatur laut permukaan dan laut dalam $23,3^{\circ} \mathrm{C}$, efisiensi Carnot sebesar 7,7\% sehingga menghasilkan daya bersih $13,40 \mathrm{MW}$.

\section{DAFTAR PUSTAKA}

Adrian, R.S. 2015. Potential Ocean Thermal Energy Conversion (OTEC) in Bali. Renewable Energy and Energy Conversion Conference and Exhibition (The 2nd) Indo EBTKE-CONEX, ISSN 2413-5453., Vol. 1:5-12.

Amano, M. and Tanaka, T. 2006. Open-Cycle OTEC Systems with Freshwater Product. Effects of Noncondensable Gases on Performance of Condenser Electrical Engineering in Japan, Vol. 154:46-54.

Anne, K. 2008. Ocean Thermal Energy Conversion. Guelph Engineering Journal, University of Guelph, Ontario, NIG 2WI, ISSN: 1916-1107., Vol. 17-23.

Avery, W. H. and Wu, Chih. 1994. Renewable Energy from the Ocean: a guide to OTEC. Oxford University Press, Inc. New York, 437 p.

Aydin, H. 2013. Performance Analysis Of A Closedcycle Ocean Thermal Energy Conversion System With Solar Preheating And Superheating. Deep Ocean Water Application Research Center, Vol 72:154-163.

Bleck, R. 2002. An oceanic general circulation model framed in hybrid isopycnic-Cartesian coordinates. Ocean Modelling, Vol. 4:55-88.

Charlier, R. H. 2003. Sustainable co-generation from the tides: A review. Renewable and Sustainable Energy Reviews 7(3), Free University of Brussels, Belgium, pp. 187-213.

Charlier, R. H., and Justus J. R. 1993. Ocean Energies: Environmental, Economic and Technological Aspects of Alternative Power Sources. 1sted., Elsevier Oceanography Series, Amsterdam, The Netherlands, 534 p.

Comfort, C.M. 2011. Environmental assessment for ocean thermal energy conversion in Hawaii. Available data and a protocol for baseline monitoring. Hawaii Natural Energy Institute University of Hawaii at Manoa Honolulu, MTS, Vol. 9:39-48.

Daniel, T.H. 1994. Deep ocean water utilization at the natural energy laboratory of Hawaii authority. In: Proceeding of Oceanology International '94. Hawaii, pp. 8-11.

Duxbury, A.B., Duxbury, A.C. and Sverdrup, K.A., 2002. Fundamentals of Oceanography. 4thed., McGraw Hill, New York, 344 p. 
Etemadi, A. 2011. Electricity Generation by the Ocean Thermal Energy. Urnia University Technology. Elsevier Ltd, Science Direct, Vol. 12:36-43.

Fanny, O. Muslim, M. Faturachman, D. Buwono, A. 2016. Study of Ocean Thermal Energy Conversion (OTEC) Generation as Project of Power Plant in West Sumatera-Indonesia, International Journal of Systems Applications, Engineering \& Development, Vol. 10:65-69.

Ilahude, A.G and A. Gordon. 1996. Thermocline Stratification Within the Indonesian Seas. J. Geophys. Res., Vol. 1(5):41-49.

James, H. 2017. An assessment of Florida's Ocean Thermal Energy Conversion (OTEC) Resource. Renewable and Sustainable Energy Reviews. Elsevier Ltd, Science Direct, Vol. 6:83-91.

Jaswar Koto. 2016. Potential of Ocean Thermal Energy Conversion in Indonesia. International Journal of Environmental Research \& Clean Energy, Vol. 4:1-7.

Lewis, A., S. Estefen, J. Huckerby, W. Musial, T. Pontes, J. Torres-Martinez. 2011. Ocean Energy. In: IPCC Special Report on Renewable Energy Sources and Climate Change Mitigation. Cambridge University Press, Cambridge, United Kingdom and New York, pp. 458-465.

Lopes, A. B., Harari, J. 2012. Use of recent geoid models to estimate mean dynamic topography and geostrophic currents in South Atlantic and Brazil Malvinas confluence. Brazilian Journal of Oceanography, Vol. $60(1): 41-48$.

Mega, L. and Syamsuddin. 2015. OTEC Potential in The Indonesian Seas. Conference and Exhibition Indonesia -New, Renewable Energy and Energy Conservation. Elsevier Ltd, Science Direct, Vol. 1(2):15-22.

Mignac, C. A. S. Tanajura, A. N Santana, L. N. Lima, and Xie. J. 2015. Argo Data Assimilation into HYCOM with an EnOI Method in the Atlantic Ocean. Ocean Sci. Discuss., Vol. 11(17):33-51.

Morales, A. D. 2014. Ocean Thermal Energy Resources in Colombia. Ocean thermal energy resources in ColombiaGrupo de Oceanografía e Ingeniería Costera. OCEANICOS, Universidad Nacional, Medellín, Colombia. Renewable Energy, Vol. 7:59-69.

Nihous, G. C. 2007. Preliminary Assessment of Ocean Thermal Energy Conversion Resources. ASME, Vol. 127:7-10

Rahman, Y. 2008. OTEC : Ocean Thermal Energy Conversion. Institut Teknologi Bandung Press. Bandung, 216 hlm.

Ridho, B. 2017. Potential of $100 \mathrm{~kW}$ of Ocean Thermal Energy Conversion in Karangkelong, Sulawesi Utara, Indonesia. International Journal of Environmental Research \& Clean Energy, ISOMAse, ISSN:2502-3888, Vol.5(1):18-21.

Sands, M. D. 1980. Ocean Thermal Energy Conversion (OTEC) Programmatic Environmental Analysis. Lawrence Berkeley National Laboratory, 222 .

Solar Energy Research Institute. 1989. Ocean Thermal Energy Conversion An Overview. U.S Department of Energy, United States for America, SERI/SP-220-3024., 38 p.

Song, Y. Zhang, Y. Zhou. 2007. The Relationship Between The Thermocline and The Catch Rate of Thunnus obesus in The Tropical Areas of The Indian Ocean. In: IOTC Proceeding-WPTT-14.

Straatman, P.J.T., and van Stark, W.G.J.H.M. 2008. A new hybrid ocean thermal energy conversion - Offshore solar pond (OTEC-OSP) design: A cost Optimisation Approach, Solar Energy, Vol. 82:20-27.

Sugiyono. 2009. Metode Penelitian Kuantitatif, Kualitatif dan R\&D. Alfabeta, Bandung, 380 hlm.

Syamsuddin, M. L. 2014. OTEC Potential in The Indonesian Seas. Conference and Exhibition Indonesia - New, Renewable Energy and Energy Conservation (The 3rd Indo-EBTKE ConEx 2014). Elsevier Ltd, Science Direct, Vol. 65:215-222.

Yamaguchi, T. 2003. Deep-Sea Water Suction Technology. Furukawa Review, Vol. 1(24):75-80.Yue, W. dan X. Huang. 2005. Distribution Characteristics of Phosphorus in Core Sediments From Zhujiang River Esstuary and Its Environmental Significance. Journal of Tropical Oceanography., 24 (1): 21-27.

Zhuang, W., X. Gao, Y. Zhang, Q. Xing, L. Tosi, S. Qin. 2014. Geochemical Characteristics Of Phosphorus In Surface Sediments Of Two Major Chinese Mariculture Areas : The Laizhou Bay And The Coastal Waters Of The Zhangzi Island. Marine Pollution Bulletin.

Zhou, F., X. Gao, H. Yuang, J. Song, C. T. A. Chen, H. K. Lui, Y. Zhang. 2016. Geochemical Forms and Seasonal Variations of Phosphorus In Surface Sediments of The Eat China Sea Shelf. Journal of Marine Systems. 